\title{
Energy Harvesting Study on Single and Multilayer Ferroelectret Foams under Compressive Force
}

\author{
Zhenhua Luo, Dibin Zhu, Junjie Shi, Steve Beeby \\ Electronics and Computer Science, University of Southampton, \\ University Rd, Southampton SO17 1BJ, United Kingdom
}

and Chunhong Zhang, Plamen Proynov, Bernard Stark

The Department of Electrical and Electronic Engineering, University of Bristol, Senate House, Tyndall Ave, Bristol, City of Bristol BS8 1TH, United Kingdom

\begin{abstract}
Cellular polypropylene (PP) ferroelectret is a thin and flexible cellular polymer foam that generates electrical power under mechanical force. This work investigates single and multilayer ferroelectret PP foams and their potential to supply energy for human-bodyworn sensors. Human foot-fall is emulated using an electrodynamic instrument, allowing applied compressive force and momentum to be correlated with energy output. Peak power, output pulse duration, and energy per strike is derived experimentally as a function of force and momentum, and shown to be a strong function of external load resistance, thus providing a clear maximum energy point. The possibility of increasing pulse time and reducing voltage to CMOS compatible levels at some expense of peak power is shown. To further increase the output power, multilayer ferroelectret is presented. The synchronized power generation of each layer is studied and illustrated using simulation, and results are supported by experiments. Finally, the energy output of single-layer and multi-layer ferroelectrets are compared by charging a capacitor via a rectifier. A ten-layer ferroelectret is shown to have charging ability 29.1 times better than that of the single-layer ferroelectret. It demonstrates energy output that is capable of powering the start-up and transmission of a typical low-power wireless sensor chipset.
\end{abstract}

Index Terms - Ferroelectret, energy harvesting, polypropylene (PP), single layer, multilayer, compressive force.

\section{INTRODUCTION}

FERROELECTRET is a thin and flexible cellular polymer foam that can store charges in its internal voids [1-4], thus being able to generate electric pulse under mechanical deformation such as compression and bending [5-6]. Due to its high piezoelectric voltage constant $g_{33}[7]$, ferroelectret has already been used extensively in sensor applications, such as blood pressure pulse transducer [8], touch sensor [9], ultrasonic transducer [10], prosthetic skin [11], and accelerometer [12]. Among the ferroelectret materials that have been developed, cellular polypropylene (PP) is one of the most researched [2-6], and being one of the first commercialized ferroelectrets [13-15]. Charged cellular PP exhibits a high piezoelectric charge constant $\mathrm{d}_{33}$, which is comparable to commercial PZT [7]. It is very soft in the thickness direction, with Young's modulus in the order of $1 \mathrm{MPa}$ [16-17]. Due to its high $d_{33}$ and small Young's modulus, PP is able to

Manuscript received on 7 September 2014, in final form 9 December 2014, accepted 9December 2014. generate large electric pulse under compression force.

Energy harvesting technology that harvests power from human motion has received growing attention over the last decade. This technology enables the low-power electronics, such as wireless sensor, to be operated using the power that harvested from human activities, thus eliminates the need of recharging, and allow the devices to be self-sustainable [18-19]. The energy harvester that harvests kinetic energy from human motion is usually based on the piezoelectric effect that converts mechanical energy to electrical energy [18]. The most common piezoelectric materials used in kinetic energy harvester are lead zirconate titanate (PZT) and polyvinylidenefluride (PVDF) $[7,18-20]$. The piezoelectric effect of PZT is based on the distortion of its perovskite unit cell under mechanical deformation [21-22]. Being a piezoceramic, even though PZT has relatively high $d_{33}$, the applications of this material in wearable energy harvester have been limited by its high Young's modulus and brittle ceramic nature. PVDF, on the other 
hand, its piezoelectric effect comes from the change in the density of the molecular dipoles under mechanical deformation [7]. Despite the small Young's modulus of PVDF, which makes it easy to deform, its $d_{33}$ is an order of magnitude lower than PZT [7, 18]. Comparing to these two piezoelectric materials, charged cellular PP is light, thin, soft, and with relatively high $\mathrm{d}_{33}$ that is comparable to PZT. These properties make ferroelectret PP a promising candidate for using as the piezoelectric material in wearable energy harvester, to harvest power from human motion.

Previous studies have already investigated the vibrationbased energy harvesting of single-layer and stacked ferroelectret PP, and focusing on the maximum power output at resonance frequency [23-24]. In this work, we are focusing on the energy harvesting ability of ferroelectret PP at low frequency compression, and with large compressive forces to resemble the pressure from human walking. Due to the soft polymer nature and high $\mathrm{d}_{33}$ of ferroelectrets, the most effective way to harvest energy from them is to apply compressive force on the materials in the thickness direction. As the compressive forces by human motion mainly come from walking, it is sensible to install the ferroelectrets in the insole to harvest power. Energy harvesting using shoe-mounted piezoelectric materials have been investigated by a number of research groups [25-28]. In our work an electrodynamic test instrument is used to resemble the compressive force and frequency from footstep, as well as quantifying them, thus being able to quantitatively correlate the ferroelectrets' output energy to the force resembled human walking. The multilayer ferroelectret PP foams are also investigated in this work. The small Young's modulus of these materials allows them to be largely deformed, thus be able to generate high voltage under compressive force, but with a small current due to their dielectric material nature [23]. Multilayer ferroelectret can boost the total power output by increasing the generated voltage [29-31] or the generated current, depending if the layers are connected in series or in parallel. However, the simulation and the experimental results in this work show that the deformation and output electric pulses of each layer in the multilayer structure can be asynchronized and thus affect the total energy output. The bonding between layers is important to synchronize their deformation and increase the total power output. A synchronized ten-layer ferroelectret PP demonstrates 29.1 times the charging ability of the single-layer PP, showing energy output that is capable of powering low-power wireless sensor chipset.

In the following sections, the output pulses of ferroelectret PP under compressive force are characterized by varying the external load resistances. Then the effects of applied force and momentum on the energy output are discussed. The output pulses of single-layer ferroelectret in different walking conditions, and their negative to positive pulse ratio are shown. Also, the synchronized pulse generation of each layer in multilayer ferroelectret is studied by simulation and illustrated by experiments.
Finally, the energy output of single-layer and multilayer ferroelectret PP are compared.

\section{EXPERIMENTS}

\subsection{SAMPLE PREPARATION}

The ferroelectret PP foams were commercially purchased from Emfit Ltd. The foams were manufactured by stretching the original polyolefin material in two perpendicular directions in a continuous biaxial orientation process, then further expanded in thickness at high-pressure gas-diffusion-expansion process [32-33]. The electric charges that stored in the foams were generated by the corona charging process which involves charge separation as a result of air breakdown within the microvoids. These commercial samples were sheets in the size of $230 \mathrm{~mm} \times 210 \mathrm{~mm}$, with thickness of $70 \mu \mathrm{m}$. Their piezoelectric charge constant $d_{33}$ was measured using a PiezoMeter (PM300, Piezotest Ltd). The $\mathrm{d}_{33}$ value was determined to be approximately $300 \mathrm{pC} / \mathrm{N}$.

The PP foams were further cut into testing samples with size of $60 \mathrm{~mm} \times 70 \mathrm{~mm}$. For energy harvesting, electrodes were deposited on both sides of the samples by using a screen printer (Dek 248, Dek Printing Machines Ltd). The printing solution was silver Fabinks TC C4001 from Smart Fabric Inks Ltd. Ag electrodes with area of $50 \mathrm{~mm}$ $\times 60 \mathrm{~mm}$ were printed on both sides of the PP foams, and then the samples were cured in an oven at a temperature of $50{ }^{\circ} \mathrm{C}$ for 10 minutes, to allow the silver paste to solidify. The cross-section of the PP foam with screen printed Ag electrode is shown by the SEM image in Figure 1. The multilayer PP foams was fabricated by bonding individual layers together using Tesa double sided bonding tapes. The electrodes of each layer were connected in parallel.

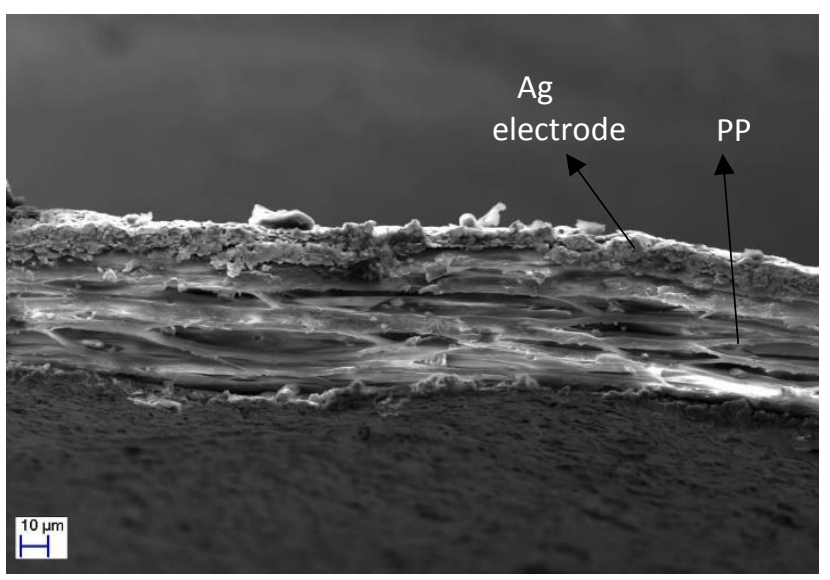

Figure 1. SEM image of a PP foam with screen printed Ag electrodes showing the cross-sectional structure.

\subsection{QUANTIFICATION OF COMPRESSIVE FORCES AND ENERGY OUTPUT}

To apply compressive forces resembling human walking, an Instron electrodynamic instrument (EletroPuls E1000, Instron Ltd) was used to quantify the applied forces. Average human walking has step frequency ranged from 0.4 to 1.45 steps/s for one foot [34-36]. By considering 
the force simulation of the Instron ElectroPuls instrument, the compressive forces that applied on the tested samples were characterized into three types of wave functions as shown in Figure 2, in order to resemble the slow walking, normal walking and fast walking of human motion. Each walking mode has a maximum force of $800 \mathrm{~N}$. The slow walking mode has step frequency of 0.4 steps/s, with each step holding at maximum force for a duration of $1 \mathrm{~s}$. The normal walking mode has step frequency of 0.8 steps/s, with each step holding at maximum force for a duration of $0.5 \mathrm{~s}$. The fast walking mode has step frequency of 1.25 steps/s, with each step holding at maximum force for a duration of $0.3 \mathrm{~s}$.

The output voltages of the PP foams under compressive force were recorded using an oscilloscope (TDS2014, Tektronix UK Ltd). The charging of a capacitor by compressing the PP foams was measured using a data logger (KUSB3102, Keithley Instruments Ltd).
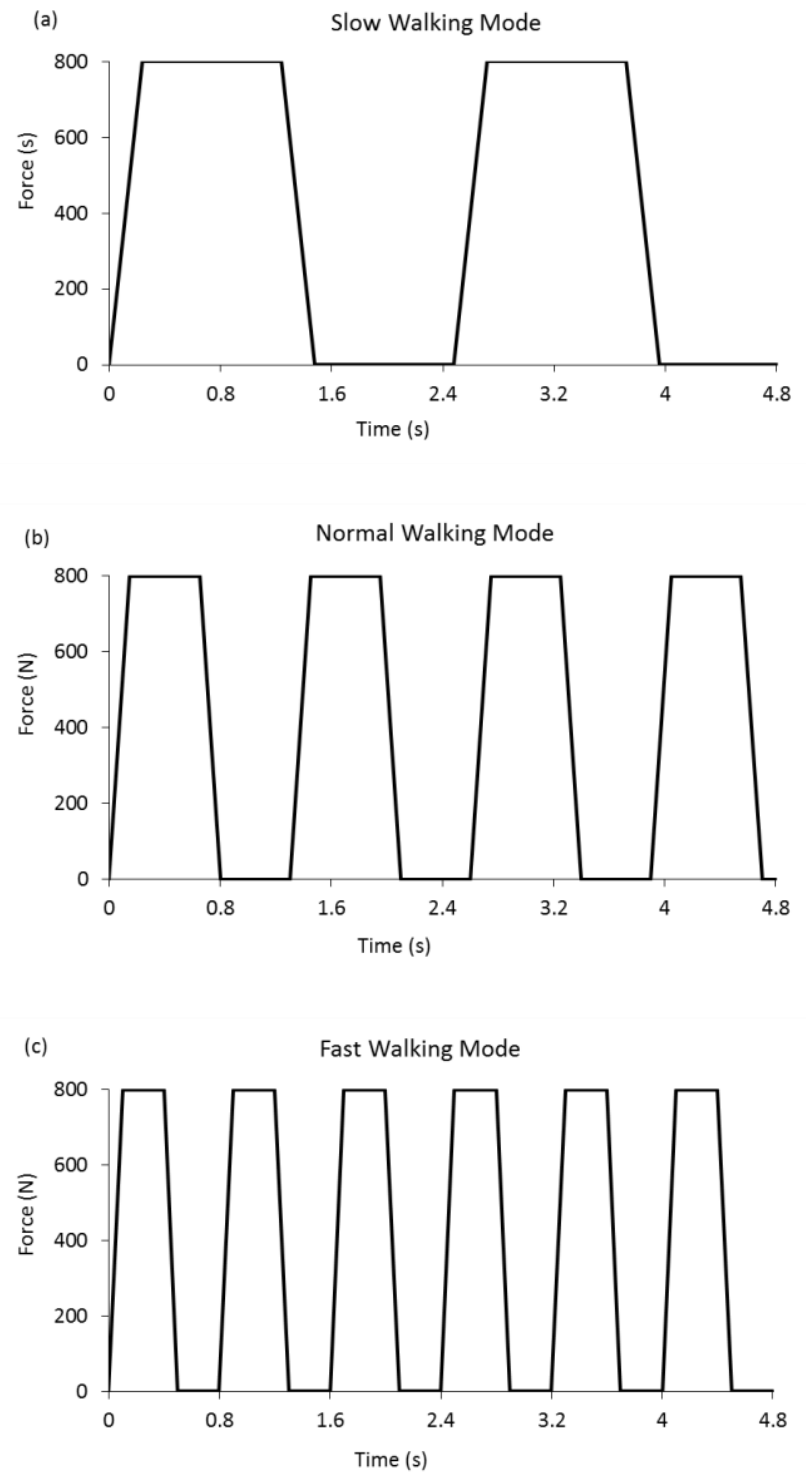

Figure 2. Wave functions of applied compressive force in slow walking mode (a), normal walking mode (b) and fast walking mode (c).

\section{RESULTS AND DISCUSSION 3.1 CHARACTERIZATION OF ENERGY OUTPUT}

The energy output of the ferroelectret PP foams under compressive force takes the form of a voltage pulse, as shown in Figure 3. The material is characterized by measuring the output voltage pulses, whilst scanning load resistance from $100 \mathrm{k} \Omega$ to $1 \mathrm{G} \Omega$, as shown in Figure 4. It shows the measured peak voltage of a single-layer PP foam under compressive forces that are applied in normal walking mode, as a function of load resistance. The voltage values used in Figure 4 are the average of measured peak voltages from three consecutive pulses. The inferred peak current increases within the range of 0.1 to $1 \mathrm{M} \Omega$, until it reaches a maximum value at $1 \mathrm{M} \Omega$, then decreases with increasing load resistance, due to the Ohmic loss [37-38]. The voltage increases with increasing load resistance. Consequently, the peak power output ( $W$ $=I V_{\text {peak }}$ ) reaches the maximum value of $168 \mu \mathrm{W}$, at a loading of $79.2 \mathrm{M} \Omega$, as shown in Figure 4. This is corresponding to area unit power output of $5.6 \mu \mathrm{W} / \mathrm{cm}^{2}$, and volume unit power output of $800 \mu \mathrm{W} / \mathrm{cm}^{3}$.

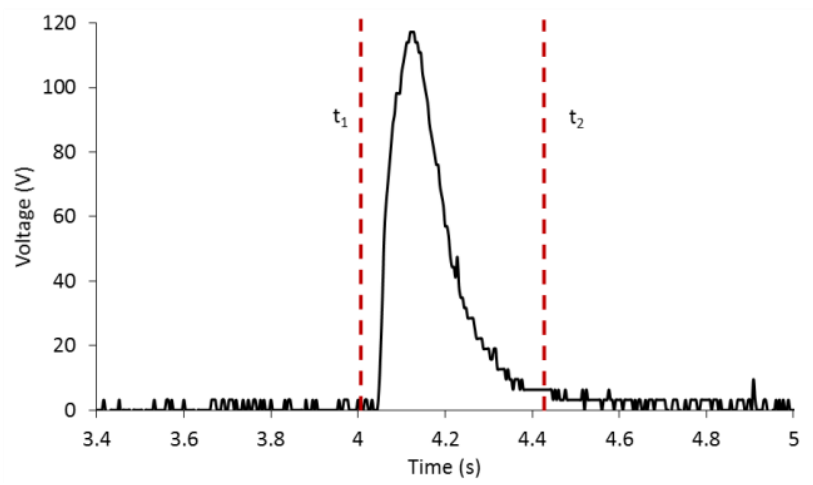

Figure 3. Energy output pulse of singe-layer ferroelectret PP at the optimal resistance of $79.2 \mathrm{M} \Omega$.

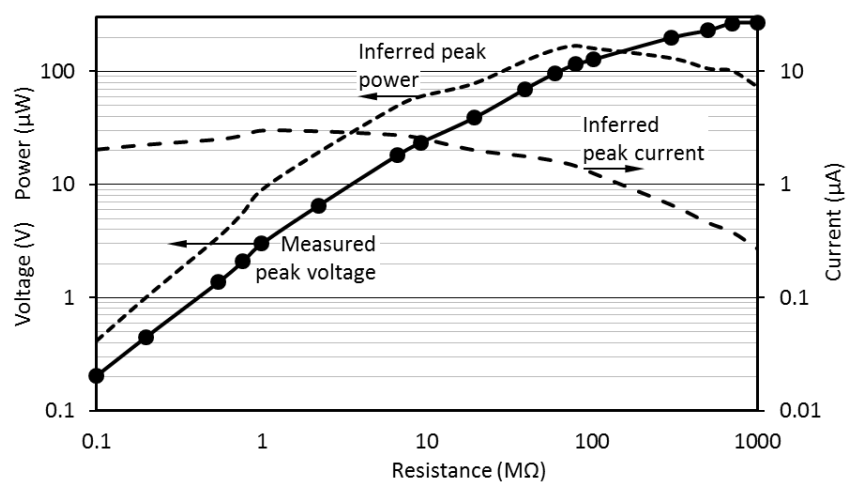

Figure 4. Measured peak voltage of output pulse of a single-layer PP foam under compressive force in normal walking mode, against resistance of purely resistive load inferred peak current and power.

The duration of the output pulses, indicated as $\Delta t=t_{1}-$ $t_{2}$ in Figure 3, are also influenced by the resistive load, as shown in Figure 5a. The pulse duration increases from 0.147 to $1.176 \mathrm{~s}$ as the load is swept from 0.1 to $1 \mathrm{G} \Omega$. Therefore, at the optimal loading of $79.2 \mathrm{M} \Omega$, where the 
instantaneous power reaches a maximum value, the duration of output pulse is approximately $0.416 \mathrm{~s}$, as shown in Figure 3. The electric energy generated by the ferrorelectret can be calculated using the formula [37, 39]:

$$
E=\left|\int_{t 1}^{t 2} V(t) \cdot I(t) d t\right|
$$

Thus in Figure 3, the electric energy generated in normal walking mode is approximately $35.1 \mu \mathrm{J}$ per pulse, corresponding to area unit energy output of $1.17 \mu \mathrm{J} / \mathrm{cm}^{2}$, and volume unit energy output of $167 \mu \mathrm{J} / \mathrm{cm}^{3}$. Using equation (1), the output energy at different resistive loads is shown in Figure 5b. It indicates that unlike peak power, the maximum energy occurs at the resistance of $500 \mathrm{M} \Omega$. At this resistance, the electric energy generated in normal walking mode is approximately $58.4 \mu \mathrm{J}$ per pulse, with area unit energy output of $1.95 \mu \mathrm{J} / \mathrm{cm}^{2}$, and volume unit energy output of $278 \mu \mathrm{J} / \mathrm{cm}^{3}$. This is corresponding to an average power output of $93.44 \mu \mathrm{W} / \mathrm{s}$.
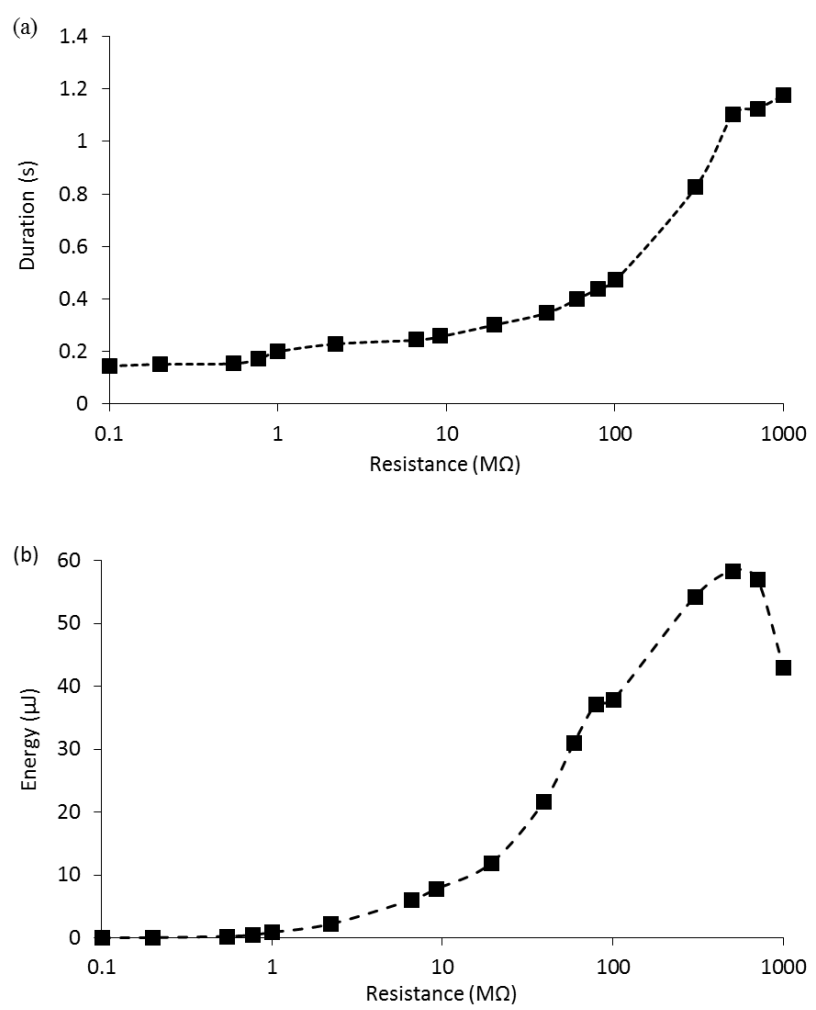

Figure 5. (a) Duration of output pulses at different resistive loads. (b) Output energy at different resistive loads.

The load resistance for maximum energy output is 500 $\mathrm{M} \Omega$. However at this load impedance, the peak voltage is in excess of $200 \mathrm{~V}$, which leads on to the following considerations: In energy harvesting applications where the energy is extracted in pulses, it is preferable that the power management circuit is input-powered [40]. Comparing to powering from the system energy storage, the advantage of input-powering is that the power management circuit is active only during the energy pulse, thus minimizes the overall quiescent losses. However, the power losses of the power management circuit are strongly influenced by the supply voltage [41-42].
Therefore, such high voltage may not be desirable for electronic circuit. It may also be desirable to increase the pulse width at the expense of energy content in order to reduce the intermittency, which in itself causes system energy loss during start-up, as shown in [43]. In addition, as many integrated circuits only work safely under a voltage stress of $5.5 \mathrm{~V}$, and a high external resistive load to the materials will make the matching from power converter being difficult in the CMOS process, it is more suitable to have output voltage in the range of 1 to $5.5 \mathrm{~V}$. At $1 \mathrm{M} \Omega$ and in normal walking mode, the output peak voltage is $3 \mathrm{~V}$ and its instantaneous current is $3 \mu \mathrm{A}$, which, once rectified and smoothed, and possibly with some voltage clamping, would be suitable to be used directly as the supply to electronic circuits. Thus $1 \mathrm{M} \Omega$ is used as the resistive load in the following measurements.

\subsection{FACTORS THAT AFFECT THE ENERGY OUTPUT}

The maximum compressive force applied on the ferroelectrets in this work is set to be $800 \mathrm{~N}$, roughly resembling a walking person with weight of $80 \mathrm{~kg}$. The effect of a person's weight on the energy output is investigated in this work by varying the quantities of compressive forces in normal walking mode. Figure 6 shows the change of peak output voltage at different applied forces, with load resistance of $1 \mathrm{M} \Omega$. The fitted line indicates that the output voltage increases linearly with increasing forces, at a rate of $3.6 \mathrm{mV} / \mathrm{N}$. The durations of output pulses remain constant with increasing applied forces. For average body weights in different age groups [44], the output voltages are within the range of 1 to $5.5 \mathrm{~V}$, which is suitable to power the electronic circuits directly.

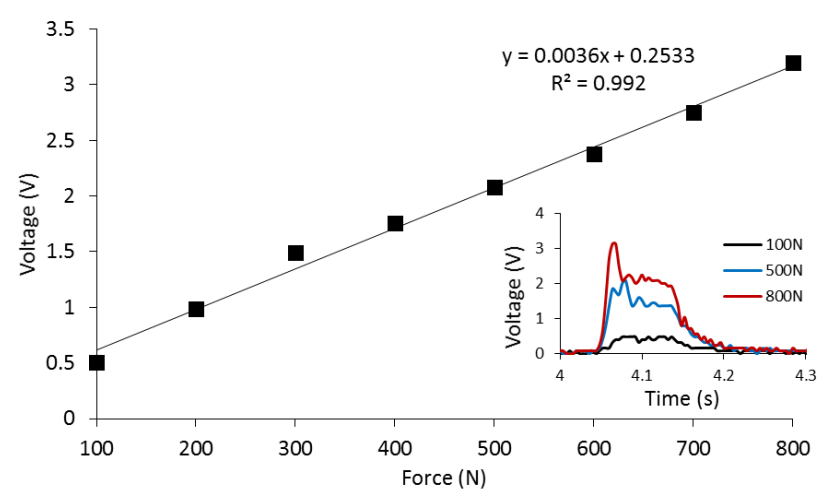

Figure 6. Peak output voltage at different applied compressive forces.

Another factor that affects the energy output is the momentum of applied compression. Figure 7 shows the output pulses of compressions applied at different momentums, with $800 \mathrm{~N}$ of maximum force. These momentums are calculated by $p=m v$. Velocity $v$ is recorded by the instrument as the speed of the compressor. At the moment when the force reaches $800 \mathrm{~N}$, the mass $m$ can be considered as $80 \mathrm{~kg}$, being similar to a static force of $800 \mathrm{~N}$. A compression with high momentum produces an output pulse with high voltage, but with smaller 
duration than those ones with smaller momentum. For example, in slow walking mode, the compressor is applied at a speed of $7 \mathrm{~mm} / \mathrm{s}$, resembling a foot stepping on the ground with momentum of $0.56 \mathrm{kgms}^{-1}$. It produces a pulse with peak voltage of $1.8 \mathrm{~V}$, with duration of $0.28 \mathrm{~s}$. In normal walking mode, the compressor is applied with momentum of $0.88 \mathrm{kgms}^{-1}$, producing a pulse with peak voltage of $3.2 \mathrm{~V}$ and duration of $0.22 \mathrm{~s}$. In fast walking mode, the compressor is applied with momentum of 1.2 $\mathrm{kgms}^{-1}$, producing a pulse with peak voltage of $5.9 \mathrm{~V}$ and duration of $0.18 \mathrm{~s}$. With momentum of $1.44 \mathrm{kgms}^{-1}$, the applied force can produce a pulse with high peak voltage of $10.7 \mathrm{~V}$ and duration of $0.16 \mathrm{~s}$. This implies that during walking, the interval between each walking steps is longer than that of pulse duration. Thus there would be interval time at which no energy is harvested. However, if the forces are applied at a fast pace, in the case such as running, each step is applying on the ground with high momentum, producing pulses with high voltage. When the running pace is fast enough, such as at $6 \mathrm{~Hz}$ frequency for steps, the interval between steps is smaller than the duration of output pulse. Thus it is possible to reach a continuous power output with high voltage. These need to be taken into consideration when designing the power electronics for the energy harvester.

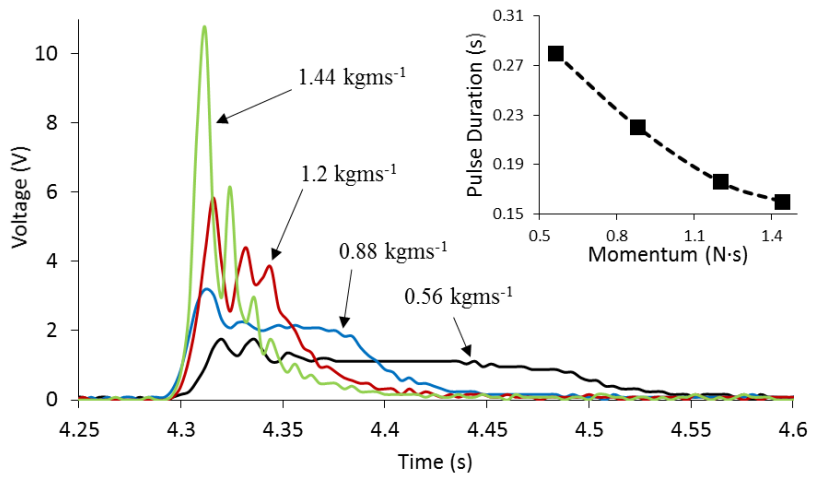

Figure 7. Output voltage pulse profiles and duration for four different momentums under a constant force of $800 \mathrm{~N}$.

\subsection{ENERGY OUTPUT OF SINGLE-LAYER FERROELECTRET}

The outputs pulses of a single-layer PP foam under compressive forces in slow walking, normal walking and fast walking mode are compared in Figure 8. The load resistance used in obtaining these data is $1 \mathrm{M} \Omega$. It shows that a single-layer PP under $800 \mathrm{~N}$ of compressive force, can generate output pulse with peak power of $3.1 \mu \mathrm{W}$ and energy of $0.43 \mu \mathrm{J}$ in slow walking mode, with peak power of $10.2 \mu \mathrm{W}$ and energy of $1.12 \mu \mathrm{J}$ in normal walking mode, with peak power of $34.1 \mu \mathrm{W}$ and energy of $3.07 \mu \mathrm{J}$ in fast walking mode. Even though fast walking has shorter duration for an output pulse, it produces an energy output almost 3 times of that in normal walking mode, and 7 times of that in slow walking mode.

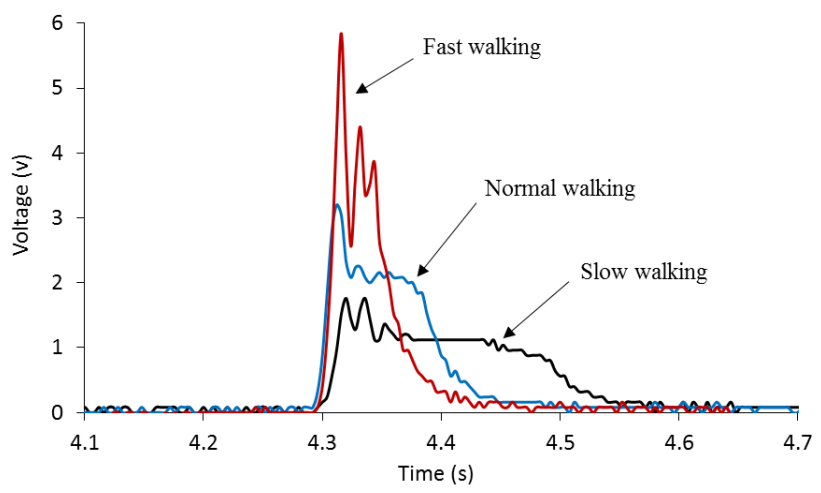

Figure 8. Output pulses of a single-layer PP foam in slow walking mode, normal walking mode and fast walking mode.

The output pulses and their rectified outputs of a single PP foam under one cycle of compressive force loading in normal walking mode are shown in Figure 9a. It indicates that the rectified output pulse can retain about $77 \%$ of the duration of the unrectified pulse. A cycle of compressive force loading produces one positive pulse when applying the force, and a negative pulse when releasing the force. As shown in Figure 9a, this negative pulse has size comparable to the positive pulse, thus produces a sizable rectified output.

However, this changes with momentum. Figure $9 \mathrm{~b}$ shows the ratio between the peak voltage of negative pulse and the peak voltage of positive pulse at different momentums. It indicates that with high momentum, such as in fast walking mode, this ratio is less than that of normal walking and slow walking, which have lower momentum when the force is applying. This can be explained by considering the change of momentum. In these walking modes with maximum force of $800 \mathrm{~N}$, the compressive forces can be considered as being from an 80 $\mathrm{kg}$ object dropping with a velocity. Between it just touching the sample and stopping completely, the change in velocity is $\Delta v$. According to the formula:

$$
F=m \times a=m \times \frac{\Delta v}{\Delta t}
$$

therefore,

$\frac{F \times \Delta t}{m}=\Delta v$

$\Delta v$ varies with momentums, but $\Delta t$ and $m$ are the same in different walking modes. Thus the force $F$ is directly proportional to $\Delta v$, and the impulse with higher momentum has higher value of $\Delta v$. As the peak voltage $V$ of an output pulse is directly proportional to the applied force in a simplified mathematical model $[6,15,45]$, the output voltage in a mode with high momentum is higher than those one with low momentum. This explains the difference in the positive output pulses in different walking modes. However, for the negative output pulses, which are produced by the deformation of the ferroelectret when releasing the compressive force, $\Delta v$ is independent of the momentums from the compressive force. Thus the peak voltages of negative pulses are similar in different walking modes, leading to the 
decrease of negative/positive peak voltage ratio as shown in Figure 9b.
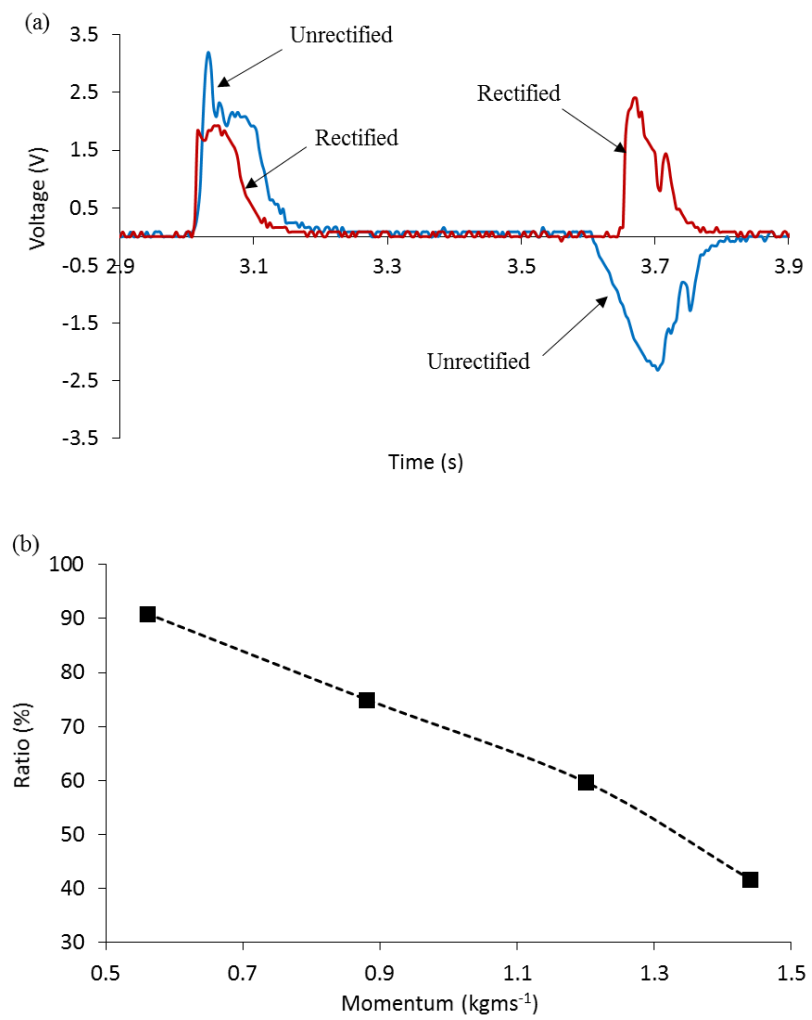

Figure 9. (a) Unrectified and rectified output pulses in normal walking mode. (b) Ratio of negative output peak voltage to positive output peak voltage at different momentums.

\subsection{SYNCHRONIZATION OF MULTILAYER OUTPUT}

A sensible method to improve the energy harvesting output of ferroelectrets is using the multilayer structure by stacking a number of PP foams together. By connecting these layers in parallel, the overall generated current can be increased. An important procedure in fabricating the multilayers foams is the bonding of layers. Figure 10 shows the simulation of elastic strain from a three-layer PP foams under $800 \mathrm{~N}$ of compressive force, with all edges in constraint condition. It indicates that the $1^{\text {st }}$ layer (top layer), deforms more than the $2^{\text {nd }}$ layer (middle layer), and the $2^{\text {nd }}$ layer deforms more than the $3^{\text {rd }}$ layer (bottom layer). As the output voltage is directly proportional to deformation $[6,45]$, which is the change of thickness in this case, this simulation implies that the $1^{\text {st }}$ layer produces higher voltage than the $2^{\text {nd }}$ layer, and the $2^{\text {nd }}$ layer produces higher voltage than the $3^{\text {rd }}$ layer.

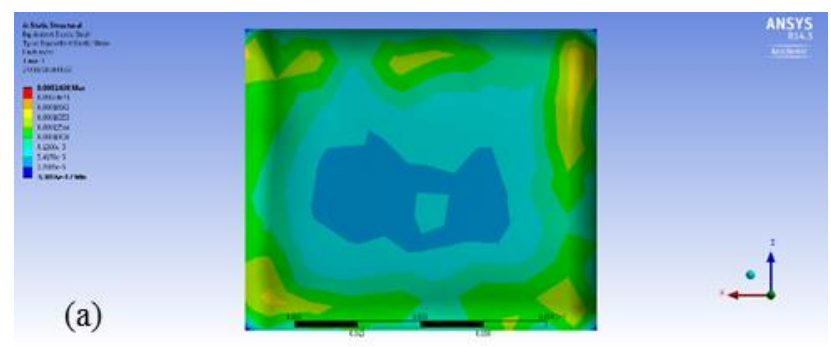

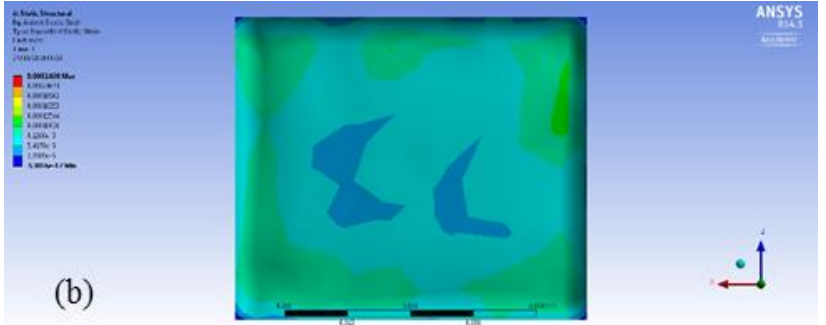

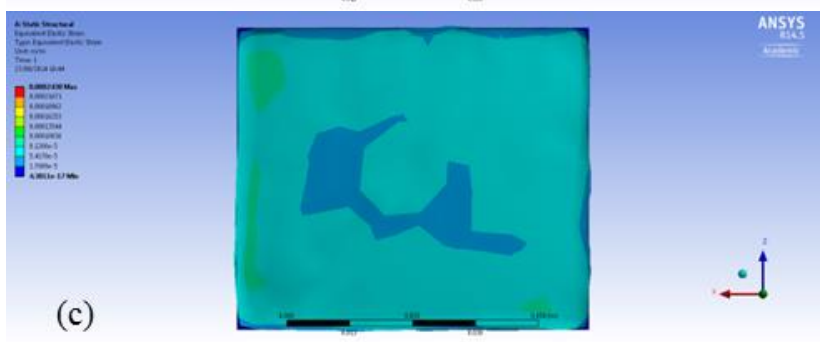

Figure 10. Simulation of elastic strain on $1^{\text {st }}$ layer (a), $2^{\text {nd }}$ layer (b) and $3^{\text {rd }}$ layer (c) in a three-layer PP foams under $800 \mathrm{~N}$ of compressive force

To support this simulation, a three-layer PP sample is fabricated by stacking the layers with all edges sealed. Insulating polymer films are inserted between the layers to prevent contact between positive and negative electrodes. Under a compressive force, the output pulses from each layer are shown in Figure 11a. It shows that the $1^{\text {st }}$ layer produces peak voltage of $5.44 \mathrm{~V}$, the $2^{\text {nd }}$ layer produces $4.88 \mathrm{~V}$, and the $3^{\text {rd }}$ layer produces $3.2 \mathrm{~V}$. This experiment result matches the prediction from simulation, implying that the output pulses are not synchronized if there is no bonding between the layers. This is the key reason for the bonding procedure in the fabrication of multilayer ferroelectrets. By bonding each layer together, the output pulses are shown in Figure $11 \mathrm{~b}$, which demonstrates a high level of synchronization.
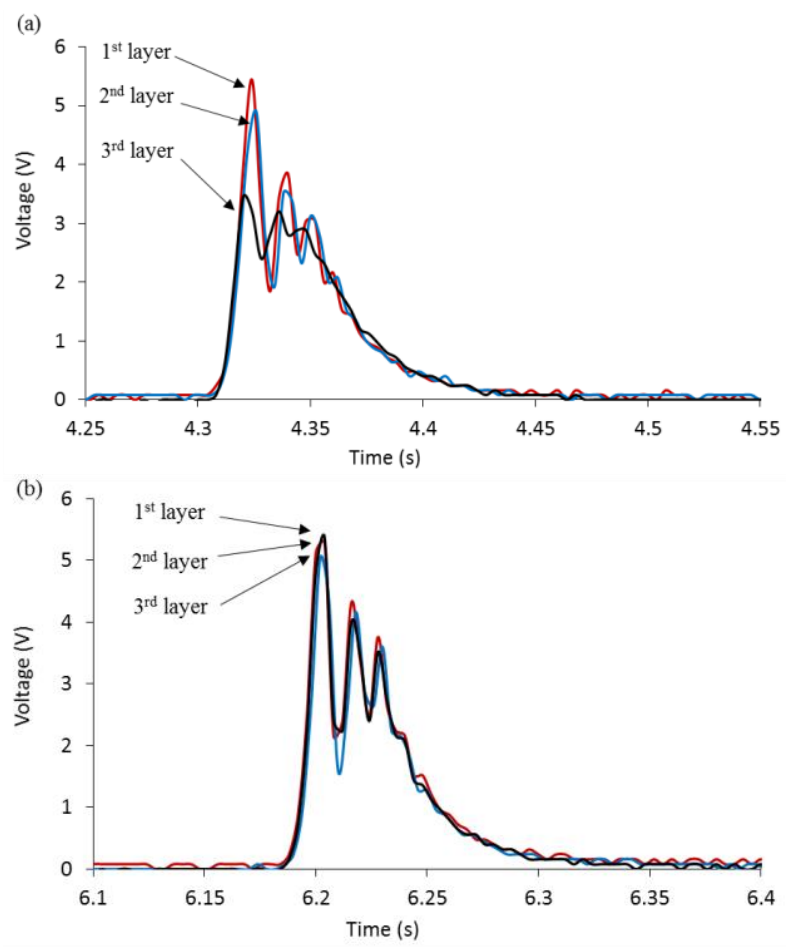

Figure 11. Output pulses from each layers in a three-layer PP foams under compressive force without bonding (a), and with bonding (b). 


\subsection{ENERGY OUTPUT OF MULTILAYER FERROELECTRET}

In this work a ten-layer PP sample is fabricated to compare with the single-layer sample for energy output. In normal walking mode, with load resistance of $1 \mathrm{M} \Omega$, the output pulses of the ten-layer and single-layer PP are shown in Figure 12 a. It shows that the ten-layer sample produces an output pulse with peak voltage of $10 \mathrm{~V}$ and a duration of $0.224 \mathrm{~s}$. Thus its peak power is $100 \mu \mathrm{W}$ and the energy output is $11.2 \mu \mathrm{J}$, which are about 10 times of those from single-layer sample. This indicates that with bonding between layers, the energy output from multilayer ferroelectret increases almost linearly with the number of layers.

A direct comparison of the energy harvested from single- and ten-layer ferroelectret materials is shown in Figure 12b. The pulses are full-wave-rectified into a 2.2 $\mu \mathrm{F}$ capacitor, and the compressive forces are set to normal walking mode. The results show that the singlelayer sample charges the capacitor to $0.87 \mathrm{~V}$ in $5 \mathrm{~s}$, while the ten-layer sample charges the capacitor to $4.7 \mathrm{~V}$ in $5 \mathrm{~s}$. The plotted capacitor energy is inferred from the voltage using

$$
E=\frac{1}{2} C V^{2}
$$

Therefore, in normal walking mode, the unit energy produced by the single-layer sample from charging the capacitor is $0.167 \mu \mathrm{J} / \mathrm{s}$, whilst the ten-layer sample is 4.86 $\mu \mathrm{J} / \mathrm{s}$, showing 29.1 times better of charging rate. Thus the ten-layer system starts up less than $10^{\text {th }}$ of the time of the single-layer system. This is due to increased harvester utilisation at higher capacitor voltages (better impedance matching) and the increase in capacitor leakage with voltage.

The charging ability of the ten-layer sample is further increased if the compressive forces were applied in a fast walking mode, due the increase in the momentum of forces and the applying frequency. The charging curves of the ten-layer sample using a $2.2 \mu \mathrm{F}$ capacitor, in normal walking and fast walking modes are compared in Figure 12c. It shows that in fast walking mode, the sample charges the capacitor to $5 \mathrm{~V}$ in 2.9 s. Thus it unit energy output by charging the capacitor is $9.5 \mu \mathrm{J} / \mathrm{s}$, which is about twice of what it produces in normal walking mode.

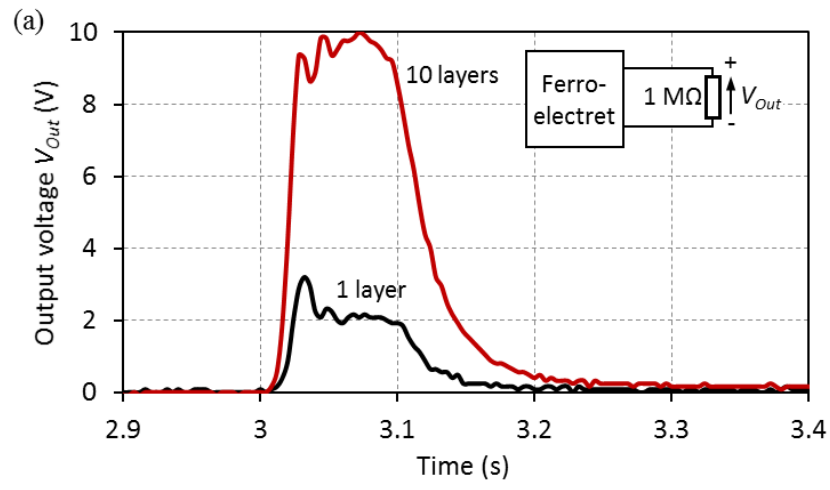

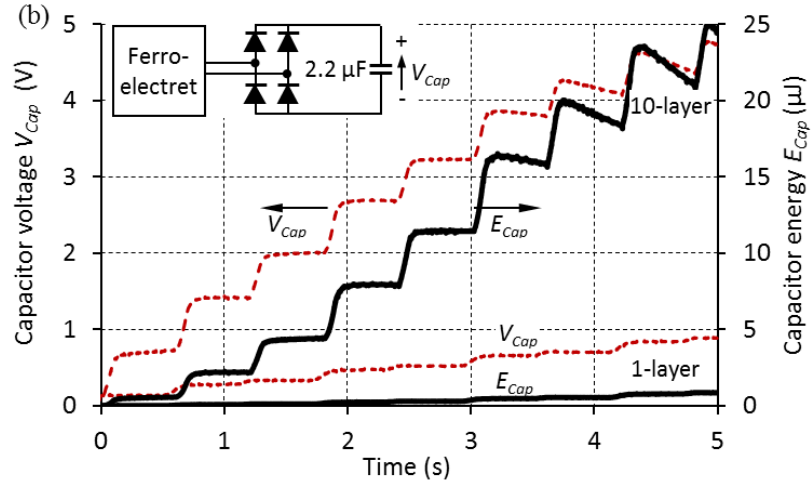

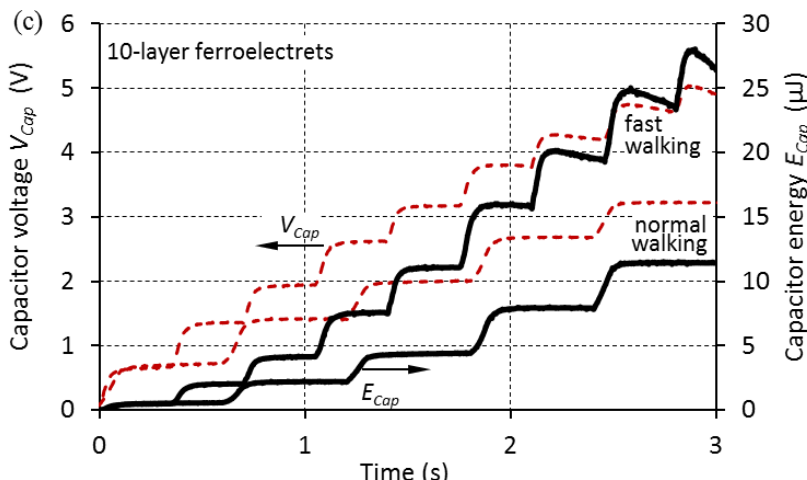

Figure 12. (a) Output voltage pulses of single-layer and ten-layer PP in normal walking mode. (b) Capacitor voltage and energy of single-layer and ten-layer PP. Normal walking mode, and rectification into a $2.2 \mu \mathrm{F}$ capacitor. (c) Capacitor voltage and energy of ten-layer PP foam under normal and fast walking conditions. Rectification into a $2.2 \mu \mathrm{F}$ capacitor.

In real applications, the total area of one insole can fit three of these ten-layer samples, each with about $2 \mathrm{~mm}$ thickness. Therefore, if used the energy output of these ferroelectrets to charge a capacitor installed in an insole, by estimation about $14.6 \mu \mathrm{J} / \mathrm{s}$ of energy can be produced from a person walking normally, and about $28.5 \mu \mathrm{J} / \mathrm{s}$ of energy if walk fast. Considering that a typical bluetooth low-energy chipset consumes 30 to $70 \mu \mathrm{J}$ of energy per transmission [46-47], depending on the size of the package, these ferroelectrets are potentially capable of powering wireless body-worn sensors for signal transmission in every 2 to $3 \mathrm{~s}$.

\section{CONCLUSIONS}

The energy harvesting ability of single layer and multilayer ferroelectret PP foams is investigated in this work. An electrodynamic instrument is used to quantify the applied compressive forces and their frequency, thus quantitatively correlates the output energy to the forces by resembling human walking. The results shows that the peak power of a single layer PP foam with electrode size of $50 \mathrm{~mm} \times 60 \mathrm{~mm}$ reaches its maximum value with an external resistance load at about 79.2 $\mathrm{M} \Omega$ in normal walking mode, whilst the maximum output energy occurs at $500 \mathrm{M} \Omega$ as the duration of output pulses increases with increasing resistances. However, considering the circuit design in real applications, $1 \mathrm{M} \Omega$ of resistance is used for the purpose of directly powering an electronics circuit. By varying the values of the applied compressive forces and 
momentums, their effects on the energy output are demonstrated. Three modes of force simulation are designed to resemble the compressive forces applied from human walking. The energy outputs of single-layer PP ferroelectret are characterized using these modes, showing output peak power of $10.2 \mu \mathrm{W}$ and energy of $1.12 \mu \mathrm{J}$ in normal walking mode. The ratios of voltages between the negative pulse and the positive pulse in these modes are also compared.

To further increase the output power, multilayer PP ferroelectret is fabricated in this work. The synchronization in outputs from each layer is studied using simulation and being supported by the experimental results. It demonstrates the importance of bonding between layers in synchronizing the energy outputs. Finally, the energy output of the single-layer and ten-layer PP ferroelectrets are compared by charging a capacitor. The ten-layer ferroelectret shows a significant improvement of energy output comparing to that of single-layer, producing pulse with peak power of $100 \mu \mathrm{W}$ and energy output of $11.2 \mu \mathrm{J}$, with charging ability 29.1 times better than the single-layer. The ten-layer PP ferroelectret demonstrates energy output that could be capable of powering the start-up and transmission of wearable electronics.

\section{ACKNOWLEDGEMENTS}

This work was performed under the SPHERE IRC funded by the UK Engineering and Physical Sciences Research Council (EPSRC), Grant EP/K031910/1.

\section{REFERENCES}

[1] G. M. Sessler, "Charge distribution and transport in polymers", IEEE Trans. Dielectr. Electr. Insul, Vol. 4, No. 5, pp. 614-628, 1997.

[2] R. Gerhard-Multhaupt, "Less can be more. Holes in polymers lead to a new paradigm of piezoelectric materials for electret transducers", IEEE Trans. Dielectr. Electr. Insul, Vol. 9, No. 5 pp. 850-859, 2002

[3] G. S. Neugschwandtner, R. Schwodiauer, S. Bauer-Gogonea, S. Bauer, M. Paajanen, and J. Lekkala, "Piezo-and pyroelectricity of a polymer-foam space-charge electret", J. Appl. Phys., Vol. 89, No. 8, pp. 4503-4511, 2001.

[4] S. Bauer, R. Gerhard-Multhaupt and G. M. Sessler, "Ferroelectrets: Soft electroactive foams for transducers", Phys. Today, Vol. 57, No. 2, pp. 37-43, 2004.

[5] S. Bauer, "Piezo-, pyro-and ferroelectrets: soft transducer materials for electromechanical energy conversion", IEEE Trans. Dielectr. Electr. Insul, Vol. 13, No. 5, pp. 953-962, 2006.

[6] J. Hillenbrand and G. M. Sessler, "Piezoelectricity in cellular electret films", IEEE Trans. Dielectr. Electr. Insul, Vol. 7, No. 4, pp. 537-542, 2000.

[7] W. Heywang, K. Lubitz and W. Wersing. Piezoelectricity: evolution and future of a technology, Springer, Berlin Heidelberg, Vol. 114, Ch. 6, pp157 -177, 2008.

[8] H. Sorvoja, V-M. Kokko, R. Myllyla, and J. Miettinen, "Use of EMFi as a blood pressure pulse transducer", IEEE. Trans. Instrum. Meas, Vol. 54, No. 6, pp. 2505-2512, 2005.

[9] I. Graz, M. Kaltenbrunner, C. Keplinger, R. Schwödiauer, S. Bauer, S. P. Lacour and S. Wagner, "Flexible ferroelectret field-effect transistor for large-area sensor skins and microphones", Appl. Phys. Letts., Vol. 89, No. 7, 073501, 2006.
[10] V. Bovtun, J. Döring, J. Bartusch, U. Beck, A. Erhard and Y. Yakymenko, "Ferroelectret non-contact ultrasonic transducers", Appl. Phys. A., Vol. 88, No. 4, pp. 737-743, 2007.

[11] S. P. Lacour, I. Graz, D. Cotton, S. Bauer and S. Wagner, "Elastic components for prosthetic skin." IEEE Int'l. Eng. Medicine and Biology Soc. (EMBC), pp. 8373-8376, 2011.

[12] J. Hillenbrand, M. Kodejska, Y. Garcin, H. Von Seggern and G. M. Sessler. "High-sensitivity piezoelectret-film accelerometers", IEEE Trans. Dielectr. Electr. Insul, Vol. 17, No. 4, pp. 1021-1027, 2010.

[13] M. Fischer, K. Kirjavainen, P. Vainikainen and E. Nyfors, "Sensor for the measurement of pressure", 20th European Microwave Conf., Vol. 2, pp. 985-989, 1990.

[14] M. Paajanen, J. Lekkala and K. Kirjavainen, "ElectroMechanical Film (EMFi) - a new multipurpose electret material", Sensors and Actuators A: Physical, Vol. 84, No. 1-2, pp. 95-102, 2000.

[15] M. Paajanen, J. Lekkala and H. Valimaki, "Electromechanical modeling and properties of the electret film EMFI", IEEE Trans. Dielectr. Electr. Insul, Vol. 8., No. 4, pp. 629-636, 2001.

[16] J. Hillenbrand and G. M. Sessler, "DC-biased ferroelectrets with large piezoelectric d 33-coefficients", J. Appl. Phys., Vol. 103, No. 7, 074103-074103, 2008

[17] M. Wegener, W. Wirges, R. Gerhard-Multhaupt, M. Paajanen, H. Minkkinen, and J. Raukola, "Enhancing the cellular structure and the electromechanical response of ferroelectrets-gas diffusion expansion of voided polypropylene films", IEEE Conf. Electr. Insul. Dielectr. Phenomena (CEIDP), pp. 36-39, IEEE, 2003.

[18] S. P. Beeby, J. M. Tudor and N. M. White, "Energy harvesting vibration sources for microsystems applications", Meas. Sci Technol., Vol. 17, No. 12, pp. R175-R195, 2006.

[19] A. Erturk and D. J. Inman, Piezoelectric energy harvesting, John Wiley \& Sons, 2011.

[20] H. B. Radousky and H. Liang, "Energy harvesting: an integrated view of materials, devices and applications", Nanotechnology, Vol. 23, No. 50, 502001, 2012.

[21] B. Jaffe, W. R. Cook and H. Jaffe, Piezoelectric Ceramics, Academic Press, London, UK, pp. 317, 1971.

[22] M. E. Lines and A. M. Glass, Principles and Applciations of Ferroelectrics and Related Materials, Oxford University Press, New York, pp. 8-14, 1977.

[23] S. Anton and K. Farinholt. "An evaluation on low-level vibration energy harvesting using piezoelectret foam", Soc. Photographic Instrumentation Eng. (SPIE) Smart Structures and Materials+ Nondestructive Evaluation and Health Monitoring, Int'1. Soci. for Optics and Photonics, pp. 83410G-83410G, 2012.

[24] P. Pondrom, J. Hillenbrand, G. M. Sessler, J. Bös, and T. Melz, "Vibration-based energy harvesting with stacked piezoelectrets", Appl. Phys. Letts., Vol. 104, No. 17, 172901, 2014.

[25] E. Camilloni, M. Carloni, M. Giammarini, and M. Conti, "Energy harvesting with piezoelectric applied on shoes", Soc. Photographic Instrumentation Eng. (SPIE), Microtechnologies, International Society for Optics and Photonics, pp. 876405-876405, 2013.

[26] J. G. Rocha, L. M. Goncalves, P. F. Rocha, M. P. Silva, and S. Lanceros-Mendez, "Energy harvesting from piezoelectric materials fully integrated in footwear." IEEE Trans. Industr. Electronics, Vol. 57, No. 3, pp. 813-819, 2010.

[27] M. L. M. Saez, Energy Harvesting from Passive Human Power, Ph.D. Thesis, Electronic Engineering, Polytechnic University of Catalonia, 2004

[28] R. Balma and T. Kaya, "Battery-Free Energy Scavenging Applications and Power Conditioning Circuit", Proceedings of the American Society for Engineering Education (ASEE) North Central Section Conf., pp. 1-7, 2012.

[29] J. Hillenbrand and G. M. Sessler, "High-sensitivity piezoelectric microphones based on stacked cellular polymer films (L)", J. Acoustical Soc. Amer., Vol. 116, No. 6, pp. 3267-3270, 2004.

[30] M. Wegener and W. Wirges. "Optimized Electromechanical Properties and Applications of Cellular Polypropylene-a New Voided Space-Charge Electret Material", The Nano-Micro Interface: Bridging the Micro and Nano Worlds, Wiley-VCH, Weinheim, pp. 303-317, 2004. 
[31] M. Wegener, S. Bergweiler, W. Wirges, A. Pucher, E. Tuncer, and R. Gerhard-Multhaupt, "Piezoelectric two-layer stacks of cellular polypropylene ferroelectrets: Transducer response at audio and ultrasound frequencies", IEEE Trans., Ultrasonics, Ferroelectrics and Frequency Control, Vol, 52, No. 9, pp. 1601-1607, 2005.

[32] K. Kirjavainen, "Electromechanical film and procedure for manufacturing same", U.S. Patent No. 4654 546, 1987.

[33] M. Wegener, W. Wirges, R. Gerhard-Multhaupt, M. Dansachmüller, R. Schwödiauer, S. Bauer-Gogonea, S. Bauer, M. Paajanen, H. Minkkinen, and J. Raukola, "Controlled inflation of voids in cellular polymer ferroelectrets: Optimizing electromechanical transducer properties", Appl. Phys. Letts., Vol. 84, No. 3, pp. 392-394, 2004.

[34] J. E. A. Bertram, "Constrained optimization in human walking: cost minimization and gait plasticity", J. Experimental Biology, Vol. 208, No. 6, pp. 979-991, 2005.

[35] J. E. A. Bertram and A. Ruina, "Multiple walking speed-frequency relations are predicted by constrained optimization", J. Theoretical Biology, Vol. 209, No. 4 pp. 445-453, 2001.

[36] G. A. Cavagna and P. Franzetti, "The determinants of the step frequency in walking in humans", J. Physiology, Vol. 373, No. 1, pp. 235-242, 1986.

[37] Z. Guang, Z-H. Lin, Q. Jing, P. Bai, C. Pan, Y. Yang, Y. Zhou and Z. L. Wang, "Toward large-scale energy harvesting by a nanoparticle-enhanced triboelectric nanogenerator", Nano Letters, Vol. 13, No. 2, pp. 847-853, 2013.

[38] T-C. Hou, Y. Yang, H. Zhang, J. Chen, L-J. Chen and Z. L. Wang, "Triboelectric nanogenerator built inside shoe insole for harvesting walking energy", Nano Energy, Vol. 2, No. 5, pp. 856-862, 2013.

[39] S. Wang, L. Lin and Z. L. Wang, "Nanoscale triboelectric-effectenabled energy conversion for sustainably powering portable electronics", Nano Letters, Vol. 12, No. 12, pp. 6339-6346, Supplementary Discussion S3, 2012.

[40] Y. Rao, K. M. McEachern and D. P. Arnold, "A compact humanpowered energy harvesting system", J. Phys.: Conf. Series, Vol. 476, No. 1, pp. 012011, IOP Publishing, 2013.

[41] A. P. Chandrakasan, S. Sheng and R. W. Brodersen, "Low-power CMOS digital design", The Institute of Electronics, Information and Communication Engineers (IEICE) Trans. Electronics, Vol. 75 No. 4, pp. 371-382, 1992.

[42] V. Kursun, S. G. Narendra, V. K. De and E. G. Friedman, "Lowvoltage-swing monolithic dc-dc conversion", IEEE Trans. Circuits and Systems II: Express Briefs, Vol. 51, No. 5, pp. 241-248, 2004.

[43] G. Yang, G, B .H. Stark, S. J. Hollis and S. G. Burrow, "Challenges for energy harvesting systems under intermittent excitation", IEEE J. Emerging and Selected Topics in Circuits and Systems, doi:10.1109/JETCAS.2014.2337172.

[44] C. L. Ogden, M. D. Carroll and K. M. Flegal. "High body mass index for age among US children and adolescents, 2003-2006", J. Amer. Medical Association, Vol. 299, No. 20, pp. 2401-2405, 2008.

[45] G. M. Sessler and J. Hillenbrand, "Electromechanical response of cellular electret films", Appl. Phys. Letters, Vol. 75, No. 21, pp. 3405-3407, 1999.

[46] S. Park, I. Locher, A. Savvides, M. B. Srivastava, A. Chen, R. Muntz and S. Yuen, "Design of a wearable sensor badge for smart kindergarten", IEEE Sixth Int'l. Sympos. Wearable Computers, (ISWC). pp. 231-238, 2002.

[47] K. Lorincz, B-R. Chen, G. W. Challen, A. R. Chowdhury, S. Patel, P. Bonato and M. Welsh, "Mercury: a wearable sensor network platform for high-fidelity motion analysis", SenSys, Vol. 9, pp. 183-196, 2009.

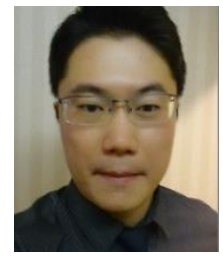

Zhenhua Luo received the B.Sc. degree in Nanotechnology in 2006, and the Ph.D. degree in 2011 from the University of New South Wales, Australia. His Ph.D. research was studying the PZT and lead-free piezoelectric ceramics. In 2009 he was working as a visiting researcher in the Technical University of Darmstadt, Germany, to research the lead-free piezoelectric ceramics including BNT-BT and KNN. In 2012 and 2013 he worked as a R\&D manager in a LED manufacturing company to develop energy harvesting floor. He joined the University of Southampton, UK, in 2013, currently working as a research fellow in EPSRC funded SPHERE project to develop energy harvesting solutions for residential sensing environment. His research interests include piezoelectric and solar energy harvesting, advanced piezoelectric materials and nanofabrication.

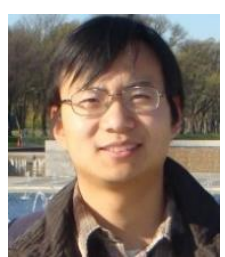

Dibin Zhu received the B.Eng. degree in information and control engineering from Shanghai Jiao Tong University, Shanghai, China, in 2004, the M.Sc. degree in RF communication systems and the Ph.D. degree in electrical and electronic engineering from the University of Southampton, Southampton, U.K., in 2005 and 2009, respectively. His $\mathrm{Ph} . \mathrm{D}$. research was on the topic of methods of frequency tuning vibration based micro-generators. He joined the University of Southampton, Southampton, U.K., in 2004, where he is currently a Research Fellow with the Electronics and Electrical Engineering Group, School of Electronics and Computer Science. His research interests include energy harvesting from various sources, e.g. vibration, airflow, human movement, solar, RF etc and their applications as well as advanced materials for energy harvesting applications.

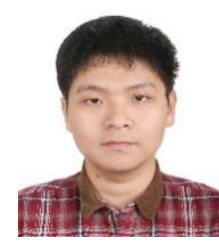

Junjie Shi was born in Nanchang, china in 1987. $\mathrm{He}$ received the B.Sc. degree from the Nanjing Institute of Technology, China in 2008, the M.Sc. degree from the University of Southampton, England, U.K in 2012. He is currently studying a Ph.D in ECS at the University of Southampton on the subject of ferroelectrets for energy harvesting applications.

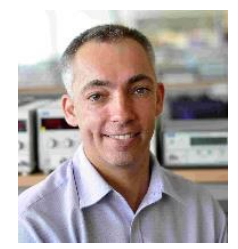

Stephen Beeby obtained a B.Eng. (Honours) degree in Mechanical Engineering from the University of Portsmouth, UK, in 1992. He obtained his $\mathrm{PhD}$ from the University of Southampton, UK, in 1998 on the subject of MEMS resonant sensors. Following his $\mathrm{PhD}$, he became a Research Fellow in the School of Electronics and Computer Science (ECS) at the University of Southampton. He has been awarded two prestigious EPSRC Research Fellowships to investigate the combination of screen printed active materials with micromachined structures and textiles for energy harvesting. Following the first Fellowship, he became a lecturer in ECS, was appointed a Reader in 2008 and was awarded a personal Chair in 2011. His research interests include energy harvesting, etextiles, MEMS, active printed materials development and biometrics. He leads the UK's Energy Harvesting Network and is Chair of the International Steering Committee for the PowerMEMS conference series. $\mathrm{He}$ is currently leading $3 \mathrm{UK}$ funded research projects and has previously been principal or co-investigator on a further 18 projects and co-ordinated 2 European Union research projects. He has coauthored/edited three books including 'Energy Harvesting for Autonomous Systems' (Artec House, Inc., Boston, London, 2010). He has given 14 invited talks and has over 200 publications and 10 patents. $\mathrm{He}$ has an H-Index of 35 with $>6000$ citations. He is a co-founder of Perpetuum Ltd, a University spin-out based upon vibration energy harvesting formed in 2004.

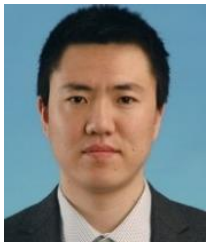

Chunhong Zhang was born in Shaanxi, China in 1986. He received the B.Sc. degree from the Xidian University, Xi'an, China in 2007, the M.Sc. degree from Xiamen University, China in 2010 and the $\mathrm{Ph} . \mathrm{D}$. degree from the Institute of Electronics, Chinese Academy of Science, China in 2013. His research interest is analogue IC design, mainly on power management ICs. Currently he is serving as a research assistant on SPHERE WP4, energy harvesting. 


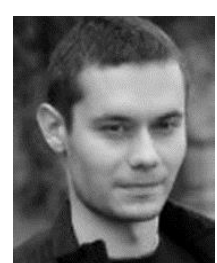

Plamen Proynov was born in Burgas, Bulgaria in 1983. He received the B.Sc. (2005) and the M.Sc. (2008) degrees in automation and control engineering from the University of Varna. From 2010 to 2014 he worked toward the Ph.D. degree in energy harvesters. He is currently a research assistant within the SPHERE project at the University of Bristol and is working on energy management, harvesting, and wireless power transfer. His research interests include low-power power electronic design for energy harvesting and low-power control strategies.

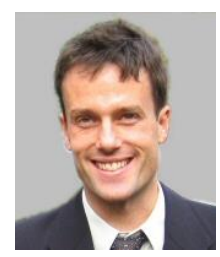

Bernard H. Stark received the M.S. degree in electrical engineering from the Swiss Federal Institute of Technology (ETH), Zurich, in 1995 and the Ph.D. degree in engineering from Cambridge University, U.K., in 2000. He spent time as a Junior Research Fellow at St. Hugh's College, Oxford, U.K., and as a member of the Control and Power Group, Imperial College, London, U.K. He is currently Reader in Electrical and Electronic Engineering at the University of Bristol, and a member of the Electrical Energy Management Research Group. His research interests include renewable power sources and power electronics. 